\title{
A Study of Two Stage Cascade Refrigeration
}

\author{
Mingli $\mathrm{He}^{1^{*}}$ \\ ${ }^{1}$ Department of Engineering and Engineering Technology, Metropolitan State University of Denver, \\ Denver, CO, USA \\ *Mingli He, E-mail: he@msudenver.edu
}

Received: March 24, 2017

doi:10.22158/wjer.v4n2p290
Accepted: April 14, 2017

Online Published: April 20, 2017

URL: http://dx.doi.org/10.22158/wjer.v4n2p290

\section{Abstract}

This paper reports the feasibility study of building a cascade refrigeration system using commercially available "off the shelf" components. The unit is to be used by a residential home or a small business with common and less expensive refrigerants and components. The research was carried out as an undergraduate project. Topics involving advanced refrigeration system is an elective course at MSU Denver. Students who participated in this project have not taken such course yet. Just in time teaching in special topics enabled the students to study the cascade refrigeration system, refrigerants behavior and natural gas behavior in order to design and build the system. As project based learning and teaching have been recognized and adopted by more and more academic units, the presented project demonstrates that complex systems can be taught, learned, and built through a project based learning process.

\section{Keywords}

cascade refrigeration system, just in time teaching, undergraduate research

\section{Introduction}

The interest of study the possibility of building a cascade refrigerator was developed from the idea of making small quantity of Liquefied Natural Gas (LNG) for household or small business usages, such as cooking or fueling a hybrid vehicle. Natural gas is a hydrocarbon gas mixture that is primarily Methane (roughly 85\%) and a mixture of other gases such as Ethane, Propane and Butane. Because of its low carbon containment, natural gas burns very cleanly. Natural gas is also used on a large scale for power production, transportation, fertilizers, aviation and many other industries. For transportation and aviation applications, the natural gas is converted to liquefied natural gas. LNG is classified as a cryogenic liquid. A cryogenic liquid is any element or compound that liquefies at a temperature below $-73^{\circ} \mathrm{C}$ at atmospheric pressure. Common forms of cryogenic liquids are liquefied Nitrogen, Oxygen, Helium and Hydrogen.

The presented research was performed in an undergraduate class with the support and assistance of 
Excel Systems HVAC, McIntosh Cryogenics LLC and Acousti-Flow. The goal was to study the possibility of building a two or three-stage cascade refrigeration system for residential LNG units with the out of shelf components, which can be manufactured and sold as a viable commercial product. According to the EPA, 30\% of total carbon output in the United States is due to petroleum fueled vehicles. Therefore, it is of great interests to obtain an alternative cleaner burning fuel. Besides cleaner burning, Natural gas is safer. If a natural gas burning vehicle is crashed, the fuel will naturally flash off into the atmosphere, where a gasoline fueled vehicle will create a puddle of fuel which is extremely dangerous. Natural gas is approximately $30 \%$ cheaper than gasoline according to naturalgas.org. Thus the need for $\mathrm{LNG}$ is predicted to increase.

The low temperature required to liquefy LNG cannot be met by a single stage refrigerator at low cost, especially when out of shelf components are used. To design a cascade refrigeration system, the basic refrigeration cycle must be understood. The refrigerant must be analyzed. A refrigerant is any fluid that will evaporate/boil at a lower temperature than the fluid being cooled. An example is the common household air conditioning unit or refrigerator. The fluid that is charged into the unit is usually R-134a, $\mathrm{R}-22$ or other designed refrigerant for the system. These refrigerants generally boil anywhere from -30 to $-5^{\circ} \mathrm{C}$. When air from the inside of a room or the inside of the refrigerator is passed over the coil, heat is transferred from the air into the refrigerant. In the process, the refrigerant absorbs heat to boil and the air releases heat becoming cooler.

As project based learning and teaching have been recognized and adopted by more and more academic units, the presented project demonstrates that complex systems can be taught, learned, and built through a project based learning process.

\section{Two Stage Cascade Refrigeration System}

\subsection{Refrigeration System}

The process of designing and building a cascade refrigeration system started with a basic refrigeration cycle and built the cascade components onto it.

A basic refrigeration cycle is shown in Figure 1. The compressor takes low pressure refrigerant which is usually saturated vapor and compresses it to the high pressure condenser, where the heat is ejected to the outside air which is usually assisted with a condenser fan. The refrigerant usually enters the condenser as superheated vapor and leaves as saturated liquid. This high pressure saturated liquid passes through a metering device, either a throttling device or a Thermal eXpansion Valve (TXV), which will cause the pressure drop in the system. Due to the change in pressure from the inlet to the outlet of the TXV, the refrigerant becomes a low pressure and low temperature liquid, which enters the evaporator. Air flowing via an evaporator fan, passes over the tubes containing the refrigerant and heat is transferred into the refrigerant thus cooling off the air and turning the refrigerant into superheated refrigerant, which is then taken into the compressor and the cycle starts over.

A cascade refrigeration system will utilize the same refrigeration cycle discussed and will integrate the 
components as shown in Figure 2.

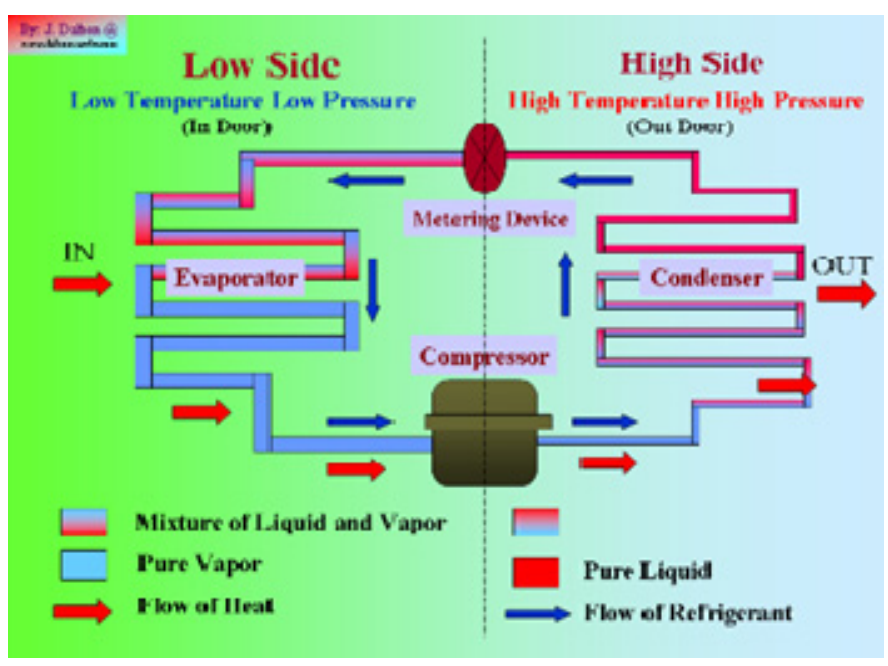

Figure 1. A Basic Refrigeration Cycle

The first stage of the cascade system will consist of the original refrigeration cycle, but the evaporator of the first stage will cool the refrigerant of the second state condenser. The cooler fluid from the second stage condenser will then go on to the second stage evaporator which will absorb the heat of the third stage condenser or the designated cooling space. This sharing of one stage evaporator to other stage condenser can be done for however many cycles is needed theoretically.

In the illustration, the evaporator for the 1st stage serves as the condenser for the 2nd stage. For the purposes of this design project, it is anticipated that at least three stages will be required to get to the final temperature needed to liquefy natural gas.

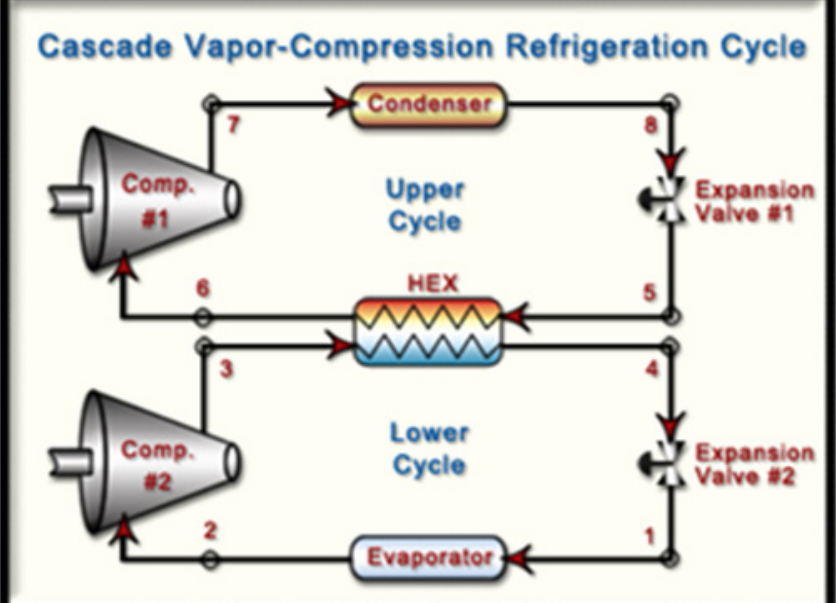

Figure 2. A Cascade Refrigeration System 


\subsection{Selection of Refrigerants}

In order for the design to be appropriate to refrigerate the designated substance, it is important to fully understand the pass for natural gas to be liquefied.

As shown in Figure 3, at $-50^{\circ} \mathrm{C}$ natural gas begins to liquefy at the top of the darker curve. The top of the dome is approximately $-55^{\circ} \mathrm{C}$ and continuous steady liquefaction occurs at approximately $-163^{\circ} \mathrm{C}$. From the figure one may conclude at $-50^{\circ} \mathrm{C}$, any heat absorbed will immediately flash the liquid to vapor, i.e., if this liquid were transported to a vessel, the energy absorbed in transit would flash the liquid to vapor. At $-100^{\circ} \mathrm{C}$, natural gas is in liquid state and depending on efficiency of the unit transporting the liquid, it would be possible to keep the gas in the liquid state. At $-163^{\circ} \mathrm{C}$ the gas is liquefied in such a manner that transportation of liquid can be easily achieved. Therefore, $-163^{\circ} \mathrm{C}$ or below should be idea temperature to liquefy and transport LNG.

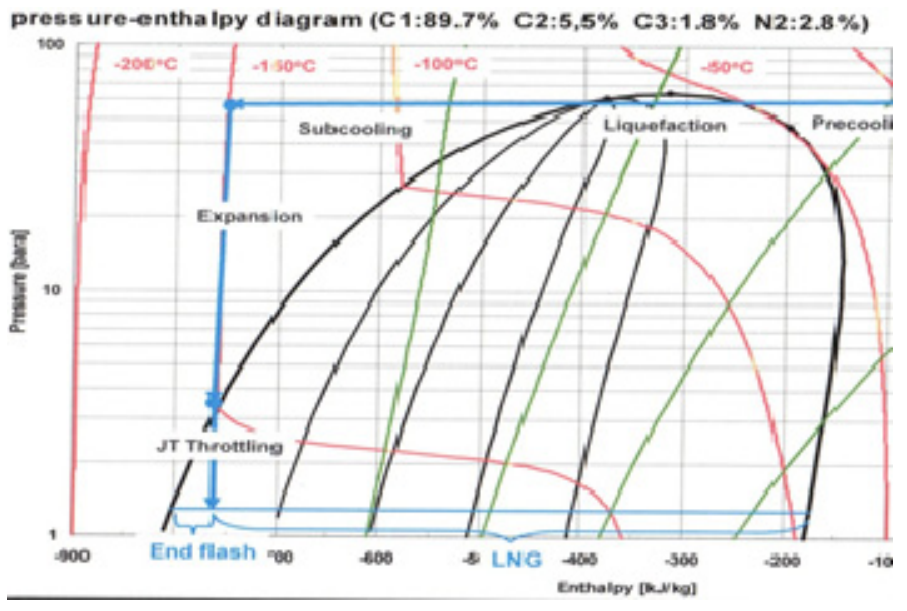

Figure 3. P-h Diagram for Natural Gas

By analyzing the pressure-temperature curves for various refrigerants three refrigerants are chosen to allow a three stage system to be built to bring the temperature of natural gas from room temperature to approximately $-160^{\circ} \mathrm{C}$. The refrigerant chosen for the first stage is MO-99 (R-438A). At a suction pressure of $15-25$ psig the refrigerant will have an ideal corresponding temperature of $-20^{\circ} \mathrm{C}$. The second stage will be charged with ethylene (R-410). Since the second stage is built exactly as the first stage, the suction pressure will again be between 15-25 psig. This will have an ideal corresponding operating temperature of $-85^{\circ} \mathrm{C}$. The third stage will be charged with methane as the refrigerant. With methane as the refrigerant and operating at $15-25$ psig suction pressure the corresponding ideal operating temperature will be $-150^{\circ} \mathrm{C}$.

\subsection{Heat Exchanger}

In the refrigeration cycle, the compressor provides the work to move the refrigerant through the system. The throttle valve is used to drop the pressure of the refrigerant in the system, which in turn controls compression ratio. Evaporators and condensers are used to absorb and reject the heat from the 
refrigeration stages. These evaporators and condensers, which for the 2nd and 3rd stages are integrated as one, are heat exchangers. Heat exchangers used in refrigeration systems vary greatly in size and structure.

When comparing different types of heat exchanger equipment one must take into account cost, manufacturability, availability and effectiveness. For this project, due to the requirement of low cost and ease of manufacture, a simple shell and tube heat exchanger was built and utilized for the combined evaporator/condenser between stages as shown in Figure 4.

Since the evaporator coil for stage one of a cascade system is also the condenser coil of stage two the following will occur in the heat exchanger:

- $\quad$ Stage one refrigerant enters as cold liquid;

- Stage one refrigerant absorbs heat from stage two refrigerant and exits as superheated vapor;

- $\quad$ Stage two refrigerant enters as superheated vapor;

- $\quad$ Stage two refrigerant exits as cold subcooled liquid.

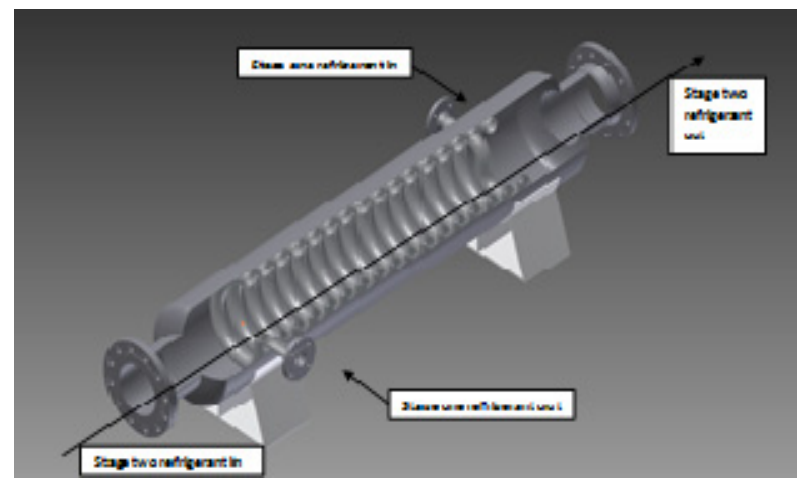

Figure 4. Heat Exchanger

The condition of the refrigerant in the system is referred as "superheat", a technical jargon in HVAC industry, which refers to the difference between the theoretical temperature and the actual temperature measured at the suction side of the compressor. The theoretical temperature can be obtained from the proper refrigerant pressure temperature charts based upon the pressure reading on the suction side of the compressor. This difference in temperature values is the result of the irreversibility of the system. In another word, the system is irreversible. In residential air conditioning units the superheat is to be maintained at $5-10^{\circ} \mathrm{C}$.

\subsection{Other Design Considerations}

Another factor to consider is mass flow rate effects on efficiency and output of system. If the mass flow rate of the refrigerant in the system is too low, the amount of heat that can be transferred out of any substance will be too low as well. The system must be designed to not only achieve the low temperature desired, but also to provide a mass flow rate through the system that can remove enough heat to produce the amount of liquefied gas needed. This part of the design of the system lies outside 
the scope of this project, as this project is intended to get to the temperature desired. However mass flow rate must be kept in mind for future design analysis.

\subsection{Building and Testing}

The components of the cascade system were provided by Excel Systems. It consists of the following components as shown and labeled in Figure 5.

Housing box internal components:

- $\quad 1.5 \mathrm{hp}$ compressor rated at a sustained operating ratio of 5:1. The operating ratio is defined as high side pressure vs. suction pressure;

- Condenser coil which is the same coil used in a common window air conditioning unit;

- Condenser fan;

- Inlet dryer to trap any condensate that may damage compressor;

- $\quad$ Electrical wiring for fan and compressor (not shown);

Housing box external components:

- $\quad$ Suction line with suction pressure gage (low side);

- Compressor discharge line with pressure gage (high side);

- $\quad$ Evaporator coil;

- $\quad$ Switch to turn unit on and off;

- 120 V Electrical supply cord (not shown).

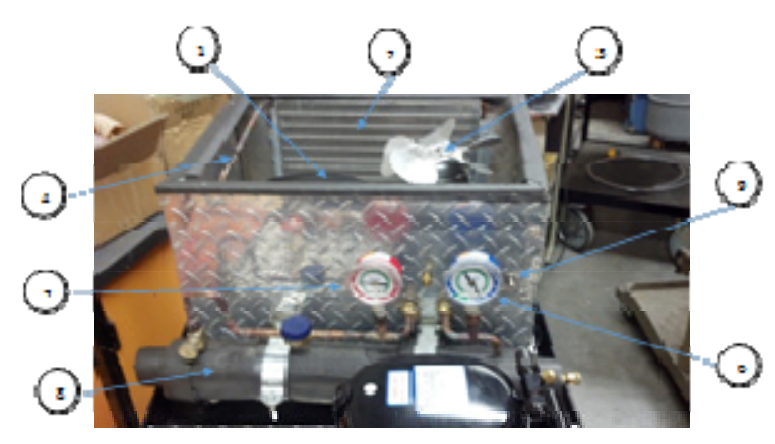

Figure 5. First Stage Refrigeration System

After stage one was tested, the second stage was constructed by mainly brazing/welding components onto the existing system. Figure 6 shows some of the components of the second stage and their relations to the first stage. 


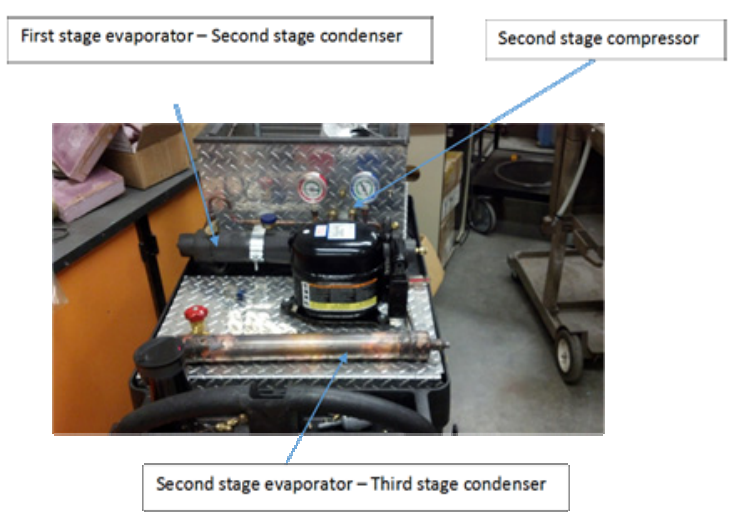

Figure 6. Second Stage of Cascade System

The operation and test of the cascade system are described as following:

- $\quad$ The system was purged of any air and moisture by the following procedure: 1) A vacuum pump was hooked up to the low side port. In fact either port may be used; 2) The pump was turned on and allowed to run for approximately 20 minutes to draw the vacuum on the system down to approximately 29 psi vacuum. This is done because air will decrease the efficiency of the unit and water will crystallize at the low temperatures once the unit is running; and 3) Once the vacuum has been drawn, the system is sealed and pressure readings were taken for an additional 20 minutes to ensure that the system has no leaks;

- Once the system is verified leak free, a container of DuPont ISCEON MO-99 refrigerant was hooked up to the system. MO-99 is the current replacement for R-12 refrigerant. R-12 is classified as a chlorofluorocarbon and production of these was phased out in 1996 as a result of the Montreal Protocol in 1987. In 1992 the Montreal Protocol was amended to phase out both chlorofluorocarbons and hydro chlorofluorocarbons and was implemented by the EPA as Title VI of the Clean Air Act;

- The container valve was opened and refrigerant was charged into the system;

- The unit turned on, to allow a suction line pressure of 35 psig and a discharge pressure of 250 psig to be obtained. This charge will be used for preliminary calculations and operations until it is deemed that more refrigerant is necessary to sustain an increased mass flow rate;

- $\quad$ The unit was run for 5 minutes to warm up the compressor;

- The throttle valve was then shut incrementally until the compressor was running at its normal ratio of operation $(5: 1)$;

- Verification that enough refrigerant was charged to allow operation and experimentation with this stage;

- $\quad$ The second stage is charged with R-410;

- The first stage was then started and allowed to run to maintain a 5:1 compression ratio;

- $\quad$ The second stage was then started and adjusted to a 10:1 compression ratio. 


\subsection{Data and Analysis}

The initial experiments were carried out running a single stage only. The data shown was from a no load run. A no load run is performed when the unit is running with no fluid load being applied to the other side of the evaporator coil. This determines the maximum cooling temperature that can be obtained by the first stage of the unit. The data also showed how long it takes to for the first stage get to the maximum cooling temperature. This data set shows the comparative temperature obtained vs. loading on the compressor. A 5:1 ratio is the maximum for continuous operation. A 10:1 ratio is the maximum if operated at this level for short periods of time. The lowest temperature recorded is $-24^{\circ} \mathrm{C}$ for a single stage no load run.

Figure 7 shows the change of evaporator temperature with respect to compression ratio over time for a typical single stage run. In the data shown, the ambient temperature for the run is $21.2^{\circ} \mathrm{C}$, which is also the evaporator temperature at the start of the run. The refrigerant is DuPont ISCEON MO-99. The figure illustrates the comparison between the temperature attained by the system in the evaporator coil and the load placed on the compressor. The time chosen was for a 30 minute cycle. The first five minutes is for the system/compressor to warm-up. The rest of the time the compressor was uniformly loaded. This timeframe can be truncated but compressor overloading should be avoided. That was the reason for the 30 minute run.

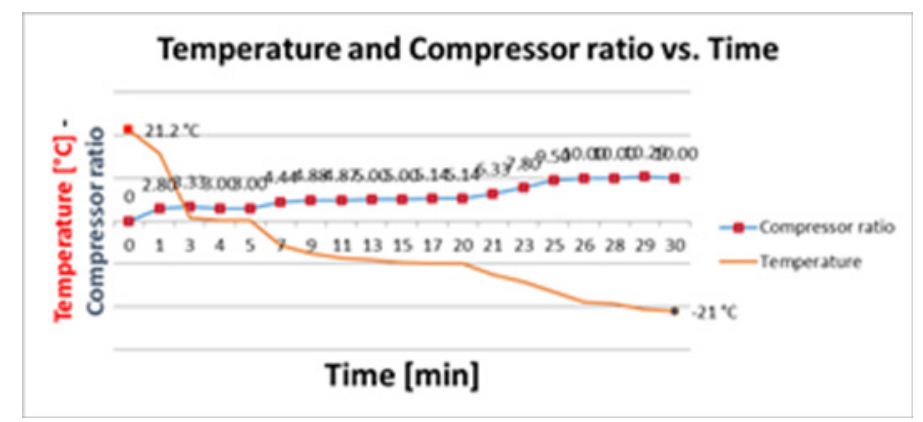

Figure 7. Evaporator Temperature and Compression Ratio vs. Time--Single Stage Run

After the success of single stage tests, the second stage was added and tested. Figure 8 shows data for a typical two stage cascade system run. The second stage had no load but was supplying a load to the first stage via condenser heat exchange. The data shows that the first stage could in fact handle the load of the second stage running and that the system could be operated steady state. The lowest temperature recorded was $-50^{\circ} \mathrm{C}$.

The ambient temperature for the reported run was $20.1^{\circ} \mathrm{C}$, which was also the evaporator temperature at the start of the run. The refrigerants were DuPont ISCEON MO-99 for the first stage and R-404 for the second stage.

While adjusting the throttle valve for the second stage, it was determined that a controlled superheat of 5-15 degrees could be maintained on the first stage with the system operating in steady state. Since the 
second stage was operating at a greatly reduced temperature, the superheat needs only to be maintained at $2-5^{\circ} \mathrm{C}$.

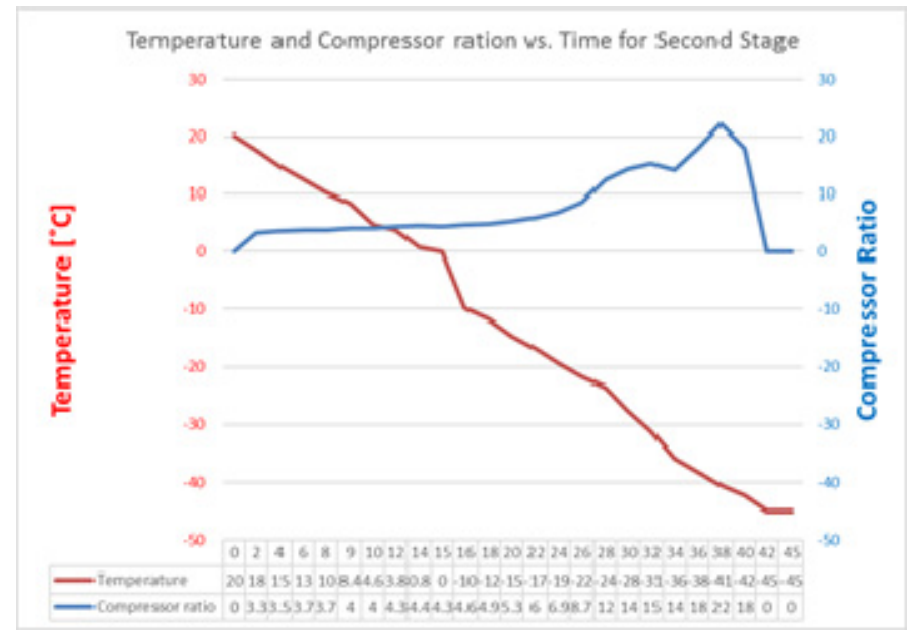

Figure 8. Second Stage Evaporator Temperature and Compression Ratio vs. Time—Cascade Run

\section{Teaching and Learning}

The challenges for a faculty conducting a project based course include engaging students in project activities in order to motivate students' desire to learn, making sure that each individual student performing well in a team environment, and providing proper guidence for students to gain proper knowledge relevant to the project.

The idea of cascade systems for liquefied natural gas was proposed to the class by Excel systems HVAC division. Three students decided to take on the challenge. After the project was selected a group meeting with the instructor was held to discuss the knowledge needed in order to accomplish the project. Understanding the fact that design and analysis of refrigeration systems especially advanced systems such as cascade refrigeration system is not introduced until thermodynamics II which is usually an elective course at undergraduate level, the instructor proposed specific topics for students to research and prepare for a mini-lecture on the subject. The topics are 1. Refrigeration system layouts, 2 . Refrigerant properties, and 3. Heat exchange design. With three students in the group, each student took on a task individually. The group and the instructor worked out the project schedule together assuming two semester project activities.

Three group meetings were scheduled, one for each research topic identified earlier. Each student was to prepare a twenty to thirty minutes presentation to present to the group the findings on assigned subject and propose preliminary recommendations for discussion. An individual meeting with the instructor was scheduled for each student before presenting to the group so that the instructor obtained a good understanding of the students' effort and understanding of the topic in order to prepare a plan to direct the discussion. The students would bring to the sessions with the results of their researches to share with the others. 
Some of the results from students' discussions were presented in the paper. Project based teaching and learning experience helped both the students and the instructor. For example, usually it a hard topic for the instructor to explain and for students to fully understand the second law of thermodynamics related topics such as reversible and irreversible processes. By observing the difference in theoretical temperature and the actual temperature measured at the suction side of the compressor as discussed in the paper, the students gained better understanding about the second law of thermodynamics and the actual applications.

\section{Discussion}

The first and second stages of the system have been integrated and in fact are reaching the designed temperatures at a steady state operation condition and in a repeatable fashion. The equipment is built with all off the shelf componentry which can be easily obtained at any HVAC warehouse. As indicated earlier, the presented project also demonstrates that a complex system can be taught, learned, and built through a project based learning process with proper just in time teaching materials added.

\section{Acknowledgements}

This project was performed with the cooperation and assistance of Excel Systems HVAC, McIntosh Cryogenics LLC and Acousti-Flow.

\section{References}

Alfa, L. (2004). The Theory behind Heat Transfer, Plate Heat Exchangers. Alfa Laval. Retrieved from http://www.alfalaval.com

Copeland Publications. (n.d.). Retrieved from http://www.hvacrinfo.com

Dennis Walsh. (n.d.). Excel Systems HVAC, personal communication.

Embraco aspera. (n.d.). North America, Inc. Retrieved from http://www.embraco.com

Gaskins, W. B., Johnson, J., Maltbie, C., \& Kukreti, A. R. (2015). Changing the Learning Environment in the College of Engineering and Applied Science Using Challenge Based Learning. IJEP, 5(1), $33-41$.

Liu, X. F., Liu, J. H., Zhao, H. L., Zhang, Q. Y., \& Ma, J. L. (2012). Experimental Study on a -60 oC Cascade Refrigerator with Dual Running Mode. Journal of Zheijiang University-SCIENCE, 375-381. https://doi.org/10.1631/jzus.A1100107

Mukherjee, R. (1996, April). Don’t let Baffling Baffle You. Chem. Eng. Progress, 92(4), 72-79.

Novak, G. M., Patterson, E. T., Gavrin, A. D., \& Christian, W. (1999). Just-in-Time Teaching: Blending Active Learning with Web Technology. Upper Saddle River, NJ: Prentice Hall.

$\begin{array}{lllllll}\text { Pressure-Enthalpy } & \text { Chart for } & \text { Methane. } & \text { (n.d.). } & \text { Retrieved } & \text { from } \\ \text { http://www.thecheworld.com/data/methane/ph-si.pdf } & & & \\ \text { Pressure-Enthalpy } & \text { chart } & \text { for } & \text { MO99. } & \text { (n.d.). } & \text { Retrieved } & \text { from } \\ & & & 299 & & & \end{array}$


http://www2.dupont.com/ISCEON/en_US/assets/downloads/k23738_ISCEON_MO99_pressure_e nthalpy_si.pdf

Tubular Exchanger Manufacturers Association. (1998). Standards of the Tubular Exchanger Manufacturers Association (7th ed.). TEMA, New York.

Yunus, C. (2014). Thermodynamics-An Engineering Approach (8th ed.). McGraw-Hill. 